\title{
Breeding and transgenesis as means of decreasing adiposity in farm animal species: practice and promise
}

\author{
BY H. D. GRIFFIN ${ }^{1}$, N. D. CAMERON ${ }^{2}$ and G. BULFIELD ${ }^{1}$ \\ Departments of ${ }^{1}$ Cellular and Molecular Biology and ${ }^{2}$ Biometrical Genetics, AFRC Institute of \\ Animal Physiology and Genetics Research, Edinburgh Research Station, Roslin, \\ Midlothian EH25 9PS
}

\begin{abstract}
Although there has been an increasing demand for leaner meat from consumers, modern strains of commercial livestock species still contain large amounts of fat. At present cattle, sheep and pig carcasses in the UK contain about 25,25 and $20 \%$ of dissectible fat respectively (Kempster et al. 1986; Wood et al. 1991). Whereas poultry has a reputation of providing lean meat, this is more a reflection of the distribution of adipose tissue depots in birds than of their overall leanness. Current commercial strains of broiler chicken contain about $15 \%$ of their body-weight as fat, ducks $25-30 \%$ and turkeys from 8 to $15 \%$ depending on age and sex (Griffin \& Whitehead, 1982; Powell, 1986).

The first part of the present paper examines the potential for reducing fat content in the major livestock species (i.e. cattle, sheep, pigs and poultry) by conventional selection. The second part briefly reviews initial attempts to improve lean tissue growth by the the use of gene transfer. Some of the more recent technical developments in molecular genetics that may encourage further studies on the manipulation of body composition are described.
\end{abstract}

\section{GENETIC VARIATION IN FATNESS IN FARM ANIMAL SPECIES}

Genetic variation in livestock species occurs both between breeds and within breeds, and reduction in carcass fat content could be achieved either by breed substitution or by selection for leanness within breeds.

In practice, the scope for breed substitution is limited because different breeds may be suited to different production systems. For example, when the objective is to produce carcasses of fixed fat content, then the larger breeds would be expected to produce heavier and older progeny than those of the smaller breeds. However, the Texel breed of sheep is significantly leaner than would be expected from its growth rate and mature body-weight (Cameron \& Drury, 1985) but, in this case, breed substitution would only be viable if the lower growth rate was offset by an economic premium for carcass lean content. The major genetic change in beef production in the UK over the past 10-15 years has been the introduction of large and rapidly growing continental breeds, such as the Charolais and Simmental (Meat and Livestock Commission, 1991a). These newer breeds are not significantly leaner at any given age than the traditional Hereford sire breed that they have replaced. Because fatness increases with age, the more rapid growth of larger breeds means that they could be slaughtered at a younger age when they would be leaner. In practice, the body composition of beef carcasses produced in the UK has changed very little over the past 10-15 years (Kempster et al. 1986; Wood et al. 1991) and this suggests that the introduction of continental sire breeds has been used to produce larger rather than leaner carcasses. 
The response to selection within strains is proportional to the genetic variation of the trait and the accuracy of selection, and inversely proportional to the generation interval. Smith (1984) reviewed the influence of these factors on the possible rate of change in body composition in each of the major livestock species (i.e. cattle, sheep, pigs and chickens). He considered that genetic variation and accuracy of selection were similar in all four species. The selection intensity that can be applied varies greatly according to species and sex: from 1:100 in male chickens to no more than 1:3 over several years in cows. Generation intervals also vary from less than 1 year in poultry species to up to 6 years in cattle.

Taking all these variables into account, Smith (1984) estimated that the rates of reduction in the percentage of fat in the carcass that could be achieved by conventional selection in cattle, sheep, pigs and poultry were $0.5,0.9,1.6$ and $2 \cdot 2 \%$ per annum. This is an underestimate in the case of poultry because commercial breeding companies achieve generation times of between 6-7 months rather than the 1 year assumed by Smith (1984). The use of multiple ovulation and embryo transfer would increase the selection intensity that can be applied to traits in cattle and sheep and this could approximately double the rate of genetic progress in these species (Smith, 1984). In practice, breeders will not select on a single trait and even those committed to reducing body fat will make progress at a rate substantially less than maximal. Nevertheless, progress in reducing fatness by conventional selection would be cumulative, permanent, cost-effective and acceptable to the consumer.

\section{MEASUREMENT OF BODY COMPOSITION IN FARM ANIMALS}

Selection for leanness could be approached in a number of different ways. Selection by sib analysis is just about practical in broiler chickens and information on breeding values could be obtained from the slaughterhouse in larger livestock species. In practice, however, selection for leanness is dependent on the availability of relatively accurate measurements of body composition in live animals.

The use of ultrasound has proved the most widely applicable technique for estimating body composition in farm animals, with the modern real-time B-type scanner providing correlations of $0.5-0.7$ with dissectible fat in cattle, sheep and pigs. Ultrasonics has been used to estimate breast-meat percentage in chickens but it is not as successful at measuring fat content because of the different pattern of fat distribution between birds and mammals. Computerized X-ray or nuclear magnetic resonance (NMR) tomography have been used to provide correlations with body fat content of up to 0.9 . This greater accuracy would have substantial benefit (Simm, 1989) but the high cost of the sophisticated equipment is likely to exclude its application to commercial breeding programmes.

Biochemical measurements correlated to body composition have also been sought as a means of increasing the accuracy of selection. For example, Muller (1984) performed divergent selection on pigs using the activities of four NADPH-generating enzymes measured in biopsy samples of back fat as selection criteria. Muller (1984) reported that progress was as rapid as selection for back-fat thickness as measured ultrasonically, but did not test to determine whether a combination of ultrasonic and biochemical measurements would provide an increased rate of response. Griffin \& Whitehead (1982) found plasma very-low-density lipoprotein (VLDL) concentration in fully-fed broiler chickens was sufficiently well correlated with body fat content to act as an indirect 
measure of fatness $(r=0 \cdot 7)$. The liver is the major site of lipogenesis in birds, so a similar relationship cannot be expected in mammals where most lipid synthesis occurs in adipose tissue. Subsequent divergent selection of a male broiler grandparent line for VLDL concentration demonstrated the practicality of using low VLDL concentration as a means of selecting for leanness and improved feed efficiency (Whitehead, 1988).

A problem with using physiological measurements as markers for traits is that they can be very dependent on environmental variables. In contrast, molecular markers such as restriction fragment-length polymorphisms (RFLP) and DNA fingerprints promise to provide a means of characterizing genotypes that is unaffected by age, sex or diet. DNA fingerprints have been used to analyse segregating families resulting from a cross between lines of chicken divergently selected on abdominal fat, and two markers were identified that were associated with a low percentage of abdominal fat (Plotsky et al. 1990). In pigs, the halothane gene has been shown to map at, or close to, a locus contributing to growth and body composition. Studies on marker-assisted selection are at an early stage, but there is now a substantial effort being made to map the genomes of several livestock species and to identify markers linked to quantitative trait loci (Haley et al. 1990).

\section{PROGRESS IN SELECTION FOR LEANNESS}

Commercial selection for leanness has been most conspicuously successful in pigs and the average proportion of dissectible fat in pig carcasses in the UK fell from 31 to $20 \%$ of body-weight between 1975 and 1989 (Kempster et al. 1986; Wood et al. 1991). Most of the genetic improvement can be attributed to selection for reduced back-fat thickness using ultrasonics. The extent of reduction in fatness in pigs has given rise to concern that meat tenderness might be compromised by too little intramuscular fat. The Duroc breed of pig has about twice the amount of intramuscular fat as other breeds (Cameron et al. 1990) and Duroc $\times$ Large White crosses are now being used by some producers to improve meat quality. Any improvement is probably only partly due to an increase in intramuscular fat in the crosses, because Duroc pigs also have a somewhat different muscle fibre type compared with other breeds (Walkland, 1992).

Until recently the major emphasis on commercial breeding programmes has been on selection for growth. However, currently increased attention is being given to selection for feed efficiency and this may be accompanied by a reduction in body fat content. To date, the major impact on commercially available strains has been in ducks, in which substantial reductions have been made in body fat content by selection for individual feed conversion efficiency (Powell, 1986).

Progress in selecting leaner strains of pigs and poultry has benefited from a limited number of breeding companies and a clear understanding of the selection objectives, reinforced by obvious financial returns. The situation is more complex in the more fragmented cattle and sheep industries, in which the costs of feed for ruminants is not so obvious; there is no direct economic incentive for producing leaner carcasses and there is no clear consensus on breeding objectives. Experimental selection for leanness has been shown to be effective to varying degrees in cattle (Mrode, 1988) and sheep (Thompson, 1990). Some breed societies are beginning to develop more of a systematic approach to selection (Meat and Livestock Commission, 1991a,b), but even if these initiatives are successful the effect on the national herds/flocks is likely to be very gradual. 


\section{POSSIBLE APPLICATIONS OF GENETIC MANIPULATION}

The relative slow progress of genetic selection inevitably leaves scope for alternative approaches to altering body composition in livestock. The application of porcine somatotropin to pig production and the prospects for immunological manipulation of growth and body composition are described elsewhere in this Symposium. This section briefly considers the prospects for genetic manipulation of body composition.

The demonstration by Palmiter et al. (1982) of the increased growth of transgenic mice overexpressing the growth hormone gene stimulated a great deal of interest in the application of gene transfer to livestock species. The creation of transgenic animals by microinjection of DNA into pronuclei was soon found to be more difficult in farm animal species than in mice, but many examples of transgenic cattle, sheep and pigs have now been produced (Ward \& Nancarrow, 1991). The production of transgenic chickens still presents a major problem because of the special physiology of reproduction in birds and to date transgenic chickens have only been produced using retroviral vectors (Shuman, 1991).

Most of the transgenic experiments in pigs, sheep and cattle have involved the introduction of extra copies of genes involved in the control of growth (e.g. growth hormone, growth hormone-releasing hormone), often coupled to a metallothionein gene promoter. In transgenic pigs, for example, overexpression of growth hormone decreased body fat content and increased growth rate and feed efficiency. These benefits were accompanied by abnormal bone growth, reduced libido and anoestrus, arthritis, impaired kidney function and increased incidence of gastric ulcers and pneumonia (Pursel et al. 1989). Similar results in pigs and in cattle and sheep have been reported by other groups (Ward \& Nancarrow, 1991). The serious negative effects have been attributed to the gross overexpression of the transgenes, with the inference that better control of expression will allow more appropriate manipulation of performance.

This initial phase of interest has, therefore, been followed by the recognition that the application of gene transfer to animal production will not be at all straightforward. Microinjection of DNA is particularly inefficient in livestock species and does not allow control over the number of copies of the transgene integrated or of the site of integration. These deficiencies may be overcome by the use of embryo stem cells and homologous recombination (see Lister et al. 1992).

One of the additional problems in applying gene transfer to animal production is the general lack of knowledge about the genes that might have large effects on economically important traits (Bulfield, 1989). At least superficially, this would not seem to be an issue with regard to fat deposition, since the mechanisms controlling fatty acid synthesis and adipocyte hypertrophy have been well established.

An experiment by Kozak et al. (1991) suggests a cautionary note. They created mice carrying approximately twenty-five copies of a transgene coding glycerol phosphate dehydrogenase that produced levels of enzyme in tissues which were fifty to 200 times that produced by the single copy of the normal endogenous gene. The transgenic mice appeared to be physically and reproductively normal. The amount of brown fat was greater than that of non-transgenic litter-mate controls and both subcutaneous and peritoneal white fat depots were severely reduced in size. The authors concluded that overexpression had somehow interfered with the transition of brown fat to white fat, although the mechanism is not at all obvious.

The manipulation of genes involved in fat deposition may well, therefore, be much 
more useful, at least initially, in examining the complexity of the control of adipose tissue metabolism than in providing immediate practical solutions to the excessive fatness of current commercial strains.

This work was supported by a commission from the Ministry of Agriculture, Fisheries and Food.

\section{REFERENCES}

Bulfield, G. (1989). The biochemical control of quantitative traits. In Evolution and Animal Breeding, pp. 227-231 [W. G. Hill and T. F. C. McKay, editors]. Wallingford: CAB International.

Cameron, N. D. \& Drury, D. J. (1985). Comparison of terminal sire breeds for growth and carcass traits in crossbred lambs. Animal Production 40, 315-322.

Cameron, N. D., Warriss, P. D., Porter, S. J. \& Enser, M. B. (1990). Comparison of Duroc and British Landrace pigs for meat and eating quality. Meat Science 37, 227-248.

Griffin, H. D. \& Whitehead, C. C. (1982). Plasma lipoprotein concentration as an indicator of fatness in broilers: development and use of a simple assay for plasma very low density lipoproteins. British Poultry Science 23, 307-313.

Haley, C. S., Archibald, A., Andersson, L., Bosma, A. A., Davies, W., Fredholm, M., Geldermann, H., Groenen, M., Gustavsson, I., Ollivier, L., Tucker, E. M. \& Van de Weghe, A. (1990). The pig gene mapping project - PiGMaP. In Proceedings of the 4th World Congress on Genetics Applied to Livestock Production, vol. 13, pp. 67-70.

Kempster, A. J., Cook, G. L. \& Grantley-Smith, M. (1986). National estimates of the body composition of British cattle, sheep and pigs with special references to trends in fatness: a review. Meat Science 17, $107-138$.

Kozak, L. P., Kozak, U. C. \& Clarke, G. T. (1991). Abnormal brown and white fat development in transgenic mice overexpressing glycerol 3-phosphate dehydrogenase. Genes and Development 5, 2256-2264.

Lister, D., Archibald, A. L. \& Flint, D. J. (1992). Biotechnology in meat production. In The European Meat Industry in the 1990's: Advanced Technologies, Product Quality and Consumer Acceptability, pp. 1-15 [F. J. M. Smulders, editor]. Nijmegen: Audet Tijdschriften.

Meat and Livestock Commission (1991a). Beef Yearbook. Meat and Livestock Commission.

Meat and Livestock Commission (1991b). Sheep Yearbook. Meat and Livestock Commission.

Mrode, R. A. (1988). Selection experiments in beef cattle. Part 2. A review of responses and correlated response. Animal Breeding Abstracts 56, 155-167.

Muiler, E. (1984). Physiological and biochemical indicators of growth and composition. In Exploiting New Technologies in Animal Breeding: Genetic Developments, pp. 132-139 [C. Smith, J. W. B. King and J. C. McKay, editors]. London: Oxford Science Publications.

Palmiter, R. D., Brinster, R. L., Hammer, R. E., Trumbauer, M. E., Rosenfeld, M. G., Birnberg, N. C. \& Evans, R. M. (1982). Dramatic growth of mice that develop from eggs microinjected with metallothioneingrowth hormone fusion genes. Nature 300, 611-615.

Plotsky, Y., Cahaner, A., Haberfeld, A., Lavi, U. \& Hillel, J. (1990). Analysis of genetic association between DNA fingerprint bands and quantitative traits using DNA mixes. In Proceedings of the 4th World Congress on Genetics Applied to Livestock Production, vol. 13, pp. 133-136.

Powell, J. C. (1986). The possibilities for genetic improvement of commercial characteristics and carcass quality in the meat duck. In Duck Production Science and World Practice, pp. 184-192 [D. J. Farrel and P. Stapleton, editors]. University of New England Press.

Pursel, V. G., Pintert, C. A., Miller, K. F., Bolt, D. J., Campbell, R. G., Palmiter, R. D., Brinster, R. L. \& Hammer, R. E. (1989). Genetic engineering of livestock. Science 244, 1281-1288.

Shuman, R. M. (1991). Production of transgenic birds. Experientia 47, 897-905.

Simm, G. (1989). Current and possible future application of in vivo assessment in sheep breeding programmes. In Application of NMR Techniques on the Body Composition of Live Animals [E. Kallweit, M. Henning and E. Groeneveld, editors]. London: Elsevier.

Smith, C. (1984). Rates of change in farm livestock. Research and Development in Agriculture 1, 79-85. 
Thompson, J. M. (1990). Correlated responses to selection for growth and leanness in sheep. In Proceedings of the 4th World Congress on Genetics Applied to Livestock Production, vol. 16, pp. 266-275.

Walkland, C. (1992). Durocs add quality - but at a price. Pig Farming, March, pp. 19-20.

Ward, K. A. \& Nancarrow, C. D. (1991). The genetic engineering of production traits in domestic animals. Experientia 47, 913-922.

Whitehead, C. C. (1988), Selection for leanness in broilers using plasma lipoprotein concentration as selection criterion. In Leanness in Domestic Birds, pp. 41-58 [B. Leclercq and C. C. Whitehead, editors]. London: Butterworths.

Wood, J. D., Enser, M. \& Warriss, P. D. (1991). Reducing fat quantity: implications for meat quality and health. In Animal Biotechnology and the Quality of Meat Production [L. O. Fiems, B. G. Cottyn and D. I. Demeyer, editors]. Amsterdam: Elsevier. 